\title{
Retrofitting of refrigeration Bench Test Rig - Replacing R-12 refrigerant by $R 134$ a refrigerant
}

\author{
Kadam Sanjay V., Sutar S.S. \\ RIT Sakharale
}

\begin{abstract}
s
Retrofitting activity replaces or adds equipment to existing system to improve their energy efficiency, increase their output and extend their lifespan, while decreasing emissions. Initially the refrigeration system works on Vapor Compression cycle was loaded with the R12 refrigerant, which was causing the adverse environmental effects like global warming and Ozone depletion, So it was decided choose the alternative refrigerant for the R12 which is more eco-friendly and also more economical. The refrigerant selected for the system was R134a which has zero ODP and lesser GWP. The major advantage of choosing R134a over R12 is both are having almost the same properties so the system can run on R134a without any major changes in the system. The performance of the system almost remains the same with retrofitting of R12 system by R134a with slightly increased $C O P$ (coefficient of performance). And also it reduced cost as well as quantity of the refrigerant gets reduced. Which means R134a is more effective, eco-friendly and economical.
\end{abstract}

\section{Introduction:}

Ozone depletion describes two distinct but related phenomena observed since the late 1970s: a steady decline of about $4 \%$ per decade in the total volume of ozone in Earth's stratosphere (the ozone layer), and a much larger springtime decrease in stratospheric ozone over Earth's Polar Regions. The latter phenomenon is referred to as the ozone hole. CFCs and other contributory substances are referred to as ozone-depleting substances (ODS). Since the ozone layer prevents most harmful UVB wavelengths $(280-315 \mathrm{~nm})$ of ultraviolet light (UV light) from passing through the Earth's atmosphere, observed and projected decreases in ozone have generated worldwide concern leading to adoption of the Montreal Protocol that bans the production of CFCs. It is suspected that a variety of biological consequences such as increases in skin cancer, cataracts, damage to plants, and reduction of plankton populations in the ocean's photic zone may result from the increased UV exposure due to ozone depletion The ozone depletion potential (ODP) of a chemical compound is the relative amount of degradation to the ozone layer it can cause, with or CFC-11 (R-11) being fixed at an ODP of 1.0. Global warming potential (GWP) is a measure of how much a given mass of greenhouse gas is estimated to contribute to global warming. It is a relative scale which compares the gas in question to that of the same mass of carbon dioxide (whose GWP is by convention equal to 1 . The GWP depends on the absorption of infrared radiation by a given species, the spectral location of its absorbing wavelengths \& the atmospheric lifetime of the species. Refrigerant R-12 has great ODP and GWP therefore it was baned science 1997. The different comparative properties of R-12 and R-134a is shown in following table. Switching an older R-12 system to R-134a does not require a lot of modifications in most of the instances. Changing the accumulator or receiver-dryer, removing the old compressor oil and replacing the high pressure switch, it is possible to retrofit vapor compression system.

The term "retrofit" describes special procedures required to convert an R-12 system to use an alternative refrigerant. This will describe some facts about aftermarket options and procedures for retrofitting a refrigeration system to R-134a. R-134a is regarded as one of the safest refrigerants yet introduced, based on current toxicity data.

The mineral oil used with R-12 cannot be sufficiently transported throughout the a/c system by R-134a. Automobile manufacturers tested both PAGs and esters for refrigerant/lubricant miscibility, lubricity, chemical stability and materials compatibility. In the process of developing recommendations, they also considered the additives and conditioners present in the oils. Most - but not all - chose to use PAG lubricants in new vehicles equipped with R-134a, and are also recommending PAG lubricants for retrofits.

Table: properties of $R \mathbf{1 2} R$ - 134a

\begin{tabular}{|c|l|l|l|}
\hline Sr. No & \multicolumn{1}{|c|}{ Properties } & \multicolumn{1}{c|}{ R-12 } & \multicolumn{1}{c|}{ R-134a } \\
\hline 1 & Molecular formula & $\mathrm{CCl}_{2} \mathrm{~F}_{2}$ & $\mathrm{CH}_{2} \mathrm{FCF}_{3}$ \\
\hline 2 & Boiling Point & $-29.8^{\circ} \mathrm{C}$ & $-26.1^{\circ} \mathrm{C}$ \\
\hline 3 & Ozone Depletion potential & 1.0 & 0 \\
\hline 4 & Solubility In Water & $0.286 \mathrm{~g} / 1$ at $20^{\circ} \mathrm{C}$ & $0.15 \%$ by weight at $25^{\circ} \mathrm{C}$ \\
\hline 5 & Melting point & $-157.7^{\circ} \mathrm{C}(115.5 \mathrm{~K})$ & $-103.3^{\circ} \mathrm{C}(169.85 \mathrm{~K})$ \\
\hline 6 & Density & $1.486 \mathrm{~g} / \mathrm{cm}^{3}\left(-29.8^{\circ} \mathrm{C}\right)$ & $0.00425 \mathrm{~g} / \mathrm{cm}^{3}$ \\
\hline
\end{tabular}


IOSR Journal of Engineering

May. 2012, Vol. 2(5) pp: 952-955

\begin{tabular}{|c|l|l|l|}
\hline 7 & Appearance & Colorless gas & Colorless gas \\
\hline 8 & Critical pressure $\left(\mathrm{p}_{\mathrm{c}}\right)$ & 41.15 bar $(4.170 \mathrm{MPa})$ & 40.6 bar $(4.06 \mathrm{Mpa})$ \\
\hline 9 & Critical temperature $\left(\mathrm{T}_{\mathrm{c}}\right)$ & $112{ }^{\circ} \mathrm{C}(385 \mathrm{~K})$ & $122^{\circ} \mathrm{C}$ \\
\hline 10 & Freezing temperature & $112^{\circ} \mathrm{C}(385 \mathrm{~K})$ & $-142^{\circ} \mathrm{C}$ \\
\hline 11 & $\begin{array}{l}\text { Global Warming Potential } \\
(\mathrm{GWP})\end{array}$ & 8100 & 1300 \\
\hline
\end{tabular}

\section{Literature Review}

1. Alka Bani Agrawal and Vipin Shrivastava Retrofitting of vapour compression refrigerationtrainer by an ecofriendly refrigerant. After years of successful deliberations for tackling the grievous problem of ozone depletion, the United Nation's environmental protection agency concluded multinational agreement called "Montreal Protocol' for controlling the use of gases threatening the ozone layer. The successful implementation of the "Montreal Protocol' in developed countries is being appreciated for its significant reduction in emission level of ozone depleting substances Now it is the turn of developing countries to fulfill their obligation of Montreal Protocol. The dead line for complying with the phase out of chloroflurocarbon in developing countries like India is 2010. The refrigeration industry has accepted the challenge of chloroflurocarbons phase out and new eco-friendly refrigerant like hydroflurocarbons and hydrocarbons are replacing chloroflurocarbons in all commercial and industrial application. Vapour compression refrigeration trainer is an important equipment of thermal engineering lab of mechanical engineering department which operated using chlorofluorocarbon 12. CFC12 is the most important member of CFC refrigerants which are being targeted for phase out in India by 2010. In this paper, performance valuation of many eco-friendly hydrocarbon refrigerants for replacing $\mathrm{CFC} 12$ in the trainer has been done and a suitable drop in alternative refrigerant for retrofitting has been identified.

2. Zhijing Liu, Imam Haider, B.Y. Liu, Reinhard Radermacher Test Results of Hydrocarbon Mixtures in Domestic Refrigerator dFreezers In the first part of the present research, an R290/R600 mixture was tested as a drop-in substitute in a 20-cubic-feet, single-evaporator, autodefrost, topmount, conventional domestic refrigerator/freezer. All the hardware remained the same, only the capillary tube was lengthened to achieve the optimum performance. The best result with an optimized R290/R600 blend was 6\% savings compared to the baseline test with R12. In the second part of the research, an 18.0cubic-feet, autodefrost, topmount, domestic refrigerator was used for experiments. Having tested for the single-evaporator baseline performance, the unit was converted to a two-evaporator modified-lorenz-Meutzner cycle. The optimum performance of the modified unit yielded $14.6 \%$ and $16.7 \%$ energy savings with binary mixtures R290/nc5, and R290/R600, respectively. A ternary mixture R290/R600/n-c5 with $17.3 \%$ energy savings proved to be better than the binary mixtures. The superior transport properties of the hydrocarbon mixtures are believed to be responsible for their better test performance.

3. A.S. Dalkilic S. Wongwises A performance comparison of vapour-compression refrigeration system using various alternative refrigerants A theoretical performance study on a traditional vapour-compression refrigeration system with refrigerant mixtures based on HFC134a, HFC152a, HFC32, HC290, HC1270, HC600, and HC600a was done for various ratios and their results are compared with $\mathrm{CFC} 12, \mathrm{CFC} 22$, and $\mathrm{HFC} 134 \mathrm{a}$ as possible alternative replacements. 
EXPERIENTAL SET UP

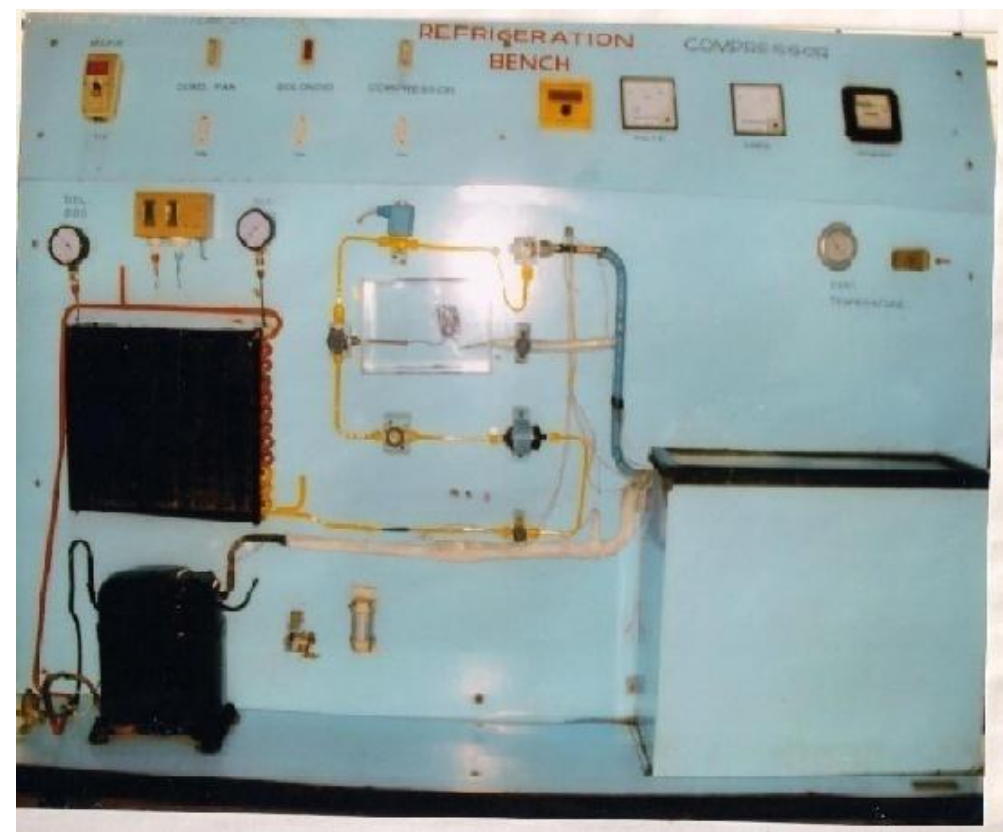

Tw1-Initial temperature of water

Tw2-final temperature of water

P1- Pressure of refrigerant at compressor suction

P2- Pressure of refrigerant at compressor delivery

T1- Temperature of refrigerant at compressor outlet

T2- Temperature of refrigerant at condenser outlet

T3- Temperature of refrigerant at compressor inlet

T4- Temperature of refrigerant at evaporator tank inlet

T5- Temperature of refrigerant at evaporator outlet

$\Delta t$ - the difference between final and initial water temperature (Tw1-Tw2

The system consists main component they are as follows Compressor, Cooling chamber, Condenser, Rota meter ,Expansion device (capillary tube) for R12, Pressure gauges, Dryer for refrigerant, Gas charging valves, Insulation, Refrigerant R134a.

Experimentation / Retrofitting were carried as follows: Initially lubricant and drier from refrigeration system was changed then leakage tested with N2 gas. This system charged with R134a gas through charging valve. Maintain fixed mass (20kg) of water in evaporator tank and note down initial temperature of water. Start condenser fan and then after two minutes start the compressor. Note all readings as given in observations after 10 minutes. The calculation was carried by following formulas'.

1. Refrigeration effect $=\mathrm{m} \mathrm{Cp} \Delta \mathrm{t} /$ time

$(\Delta \mathrm{t}=\mathrm{Tw} 1-\mathrm{Tw} 2)$

2. Actual $\mathrm{COP}=$ Refrigeration effect / actual work input to compressor.

3. Theoretical COP $=\mathrm{h} 1-\mathrm{h} 4 / \mathrm{h} 2-\mathrm{h} 1$

4. Relative $\mathrm{COP}=$ Actual $\mathrm{COP} /$ Theoretical $\mathrm{COP}$

TRIAL -1 (R12) A] Observations:

\begin{tabular}{|c|c|c|c|c|c|c|c|c|c|c|}
\hline \multirow{2}{*}{$\begin{array}{l}\text { Time } \\
\text { in min }\end{array}$} & \multicolumn{2}{|c|}{ Pressure in PSI } & \multicolumn{7}{|c|}{ Temperature in ${ }^{\circ} \mathrm{C}$} & \multirow[t]{2}{*}{$\begin{array}{l}\text { Energy meter } \\
\text { reading in } \\
\text { RPM }\end{array}$} \\
\hline & Suction & Discharge & $\mathrm{T} 1$ & $\mathrm{~T} 2$ & $\mathrm{~T} 3$ & $\mathrm{~T} 4$ & T5 & TW1 & TW2 & \\
\hline 0 & 20 & 177.5 & 75 & 47 & 32 & -30 & 19 & \multirow[t]{5}{*}{32} & \multirow[t]{5}{*}{18} & 8.2 \\
\hline 10 & 22.5 & 179 & 89 & 48 & 26 & -27 & 15 & & & 8.2 \\
\hline 20 & 22.5 & 179 & 98 & 48 & 24 & -30 & 10 & & & 8.9 \\
\hline 30 & 23 & 177 & 102 & 48 & 20 & -30 & 06 & & & 8.9 \\
\hline 40 & 23.5 & 180 & 115 & 48 & 16 & -29 & 02 & & & 8.8 \\
\hline
\end{tabular}


TRIAL -2 (R134a) B] Observation Table:

\begin{tabular}{|c|c|c|c|c|c|c|c|c|c|c|}
\hline \multirow{2}{*}{$\begin{array}{c}\text { Time in } \\
\text { min. }\end{array}$} & \multicolumn{2}{|c|}{ Pressure in PSI } & \multicolumn{7}{|c|}{ Temperature in ${ }^{\circ} \mathrm{C}$} & \multirow[t]{2}{*}{$\begin{array}{l}\text { Energy meter } \\
\text { reading in } \\
\text { RPM }\end{array}$} \\
\hline & Suction & Discharge & $\mathrm{T} 1$ & $\mathrm{~T} 2$ & $\mathrm{~T} 3$ & $\mathrm{~T} 4$ & T5 & TW1 & TW2 & \\
\hline 0 & 15 & 160 & 68 & 45 & 29 & -25 & 13 & \multirow[t]{5}{*}{29} & \multirow[t]{5}{*}{14} & 8.1 \\
\hline 10 & 22 & 170 & 93 & 51 & 24 & -24 & 12 & & & 8.1 \\
\hline 20 & 25 & 175 & 103 & 52 & 21 & -24 & 11 & & & 8.3 \\
\hline 30 & 25 & 175 & 109 & 52 & 19 & -23 & 10 & & & 8.3 \\
\hline 40 & 25 & 175 & 112 & 52 & 16 & -23 & 10 & & & 8.5 \\
\hline
\end{tabular}

\section{Result}

\begin{tabular}{|c|c|c|c|c|}
\hline Trials & Refrigerant & Actual COP & Theoretical CPO & Relative COP \\
\hline Trial 1 & R12 & 1.230 & 2.76 & 0.44 \\
\hline Trial 2 & R134a & 1.266 & 2.90 & 0.44 \\
\hline
\end{tabular}

\section{CONCLUSION:}

From the Experimental trials it was observed that the R134a is the best suited alternative refrigerant for R12 and the R134a can be used for the system which is working on the R12 refrigerant without measure changes in the system configuration. The performance of the system almost remains the same with retrofitting of R12 system by R134a. Thus the cost of replacing refrigeration system was minimized by retrofitting it with suitable means.

\section{REFERNCES:}

1. Alka Bani Agrawal and Vipin Shrivastava Retrofitting of vapour compression refrigeration trainer by an ecofriendly refrigerant Indian Journal of Science and Technology Vol. 3 No. 4 (Apr. 2010) ISSN: 0974- 6846.

2. Zhijing Liu, Imam Haider, B.Y. Liu, Reinhard Radermacher Test Results of Hydrocarbon Mixtures in Domestic Refrigerator freezers Center for Environmental Energy Engineering (CEEE) University of Maryland College Park, Maryland, USA

3. A.S. Dalkilic. S. Wongwises A performance comparison of vapour-compression refrigeration system using various alternative refrigerants. International Communications in Heat and Mass Transfer 37 (2010) 1340-1349 